\title{
O reino de Gonçalo M. Tavares como uma representação da sociedade contemporânea
}

\section{The kingdom of Gonçalo M. Tavares as a representation of the contemporary society}

Sandra Beatriz Salenave de Brito ${ }^{1}$

Doutoranda em Literatura Portuguesa pela Universidade Federal do Rio Grande do Sul e professor de Português, Espanhol e Literatura pelo Institu
RESUMO: Gonçalo M. Tavares é um escritor que segue a tendência da literatura portuguesa contemporânea de trabalhar temas universais, através de um viés filosófico, que visa desestabilizar as certezas do leitor e questionar os comportamentos da sociedade atual. Em sua tetralogia $O$ reino, Gonçalo trabalha com interrogações sociais, culturais, políticas e ideológicas, através de uma narrativa, que no cenário de guerra, mescla bondade e maldade, moralidade e corrupção, sanidade e loucura, rompendo com a visão ingênua de que o homem é formado intrinsecamente por qualidades de benevolência. Conhecer-se a si mesmo, analisando o passado e avaliando o presente, é uma ação necessária para compreender essa multiplicidade da natureza humana.

PALAVRAS-CHAVE: Gonçalo M. Tavares; Literatura portuguesa contemporânea; $O$ reino.

ABSTRACT: Gonçalo M. Tavares is a writer who follows the trend of contemporary Portuguese literature works universal themes through a philosophical bias, which aims to destabilize the reader's certainties and question the behavior of today's society. In his tetralogy The Kingdom, Gonçalo works with social, cultural, political and ideological questions, through a narrative that the war scenario, mix good and evil, morality and corruption, sanity and madness, breaking with the naive view that the man is intrinsically formed by benevolence qualities. Getting to know yourself, analyzing the past and evaluating the present, it is an action necessary to understand this multiplicity of human nature.

KEYwoRDS: Gonçalo M. Tavares; Literature Contemporary Portuguese; The Kingdom. 


\section{Breve nota sobre Gonçalo M. Tavares}

onçalo M. Tavares é um escritor português do século XXI, reconhecido por suas narrativas muito variadas, premiadas dentro e fora de Portugal. Muitas informações sobre a sua obra estão disponíveis digitalmente, seja em entrevistas no YouTube, a jornais e revistas disponíveis online, assim como em seu blog${ }^{1}$. Muitos veículos de comunicação querem dar conta da extensa produção do jovem literato que com 46 anos já publicou mais de trinta livros, editados em mais de cinquenta países.

Sua produção fundamenta-se sobre diferentes gêneros: romances, ensaios, poemas, epopeia, investigações, teatro, histórias, arquivos, atlas, enciclopédia, short movies, bloom books, $O$ reino, $O$ bairro, etc. Gonçalo Tavares opta por classificar seus escritos a partir de uma tipologia nada habitual. Seus livros são muito diferentes entre si, como se fossem escritos por diferentes autores. E essa escolha parte de sua vontade de explorar as múltiplas possibilidades da escrita literária: “De certa maneira, a minha intenção é experimentar vários caminhos: um caminho trágico, um caminho lúdico, um caminho de escrita rápida..." (TRIGO, 2014, s/p.).

Da mesma forma que Borges (1985) pondera sobre as categorias literárias e defende a negação dos gêneros, dado que a classificação depende menos dos próprios textos do que do modo como são lidos, Tavares realça a interação entre o leitor e o texto, a qual pode compor leituras diversas, quase inesgotáveis. "O livro tem um tempo de reflexão que é dado ao leitor, ao processo de leitura, que nenhuma outra arte tem" (MELLO, 2010, s/p.).

O professor universitário que dá aulas de Cultura e Pensamento Contemporâneo e de Reabilitação Psicomotora, que se graduou em esporte, fez mestrado em pintura e doutorado em literatura (COSTA e BESSANA,

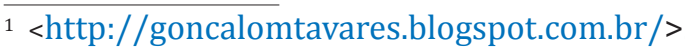

2015, s/p.), propõe a construção de diferentes pontos de vista, desde o riso solto de temas leves, como sua releitura da vida fictícia de escritores famosos presente na série $O$ bairro, até a seriedade e a reflexão sobre a subjetividade dos sujeitos após duas guerras mundiais, sendo este o foco de $O$ reino, que é objeto deste trabalho.

\section{0 romance português contemporâneo}

Freitas (2014, p.34) define o romance português contemporâneo como "a produção em prosa instaurada no Pós 25 de Abril", que passou de uma "uma literatura empenhada e militante" para "depois da metade da década de 80 , voltar-se à História numa tentativa vanguardista de busca do otimismo perdido". É essa consciência político-social que na tetralogia tavariana extrapola os limites portugueses, situando a história dos livros pretos em um tempo e espaço apenas delineados na realidade pós-Auschwitz, que estabeleceu a fronteira para o comportamento humano, demonstrando ficcionalmente como os sujeitos foram prejudicados por essa realidade.

Miguel Real (2012) volta um pouco mais no passado, demarcando o romance português contemporâneo como uma evolução que passa pelo fim da Segunda Guerra Mundial, pela perda do Império e pela integração de Portugal na Comunidade Europeia. Para o crítico português, tantas transformações políticas, históricas e sociais também abalaram as estruturas do romance contemporâneo produzido em Portugal, na criação dos personagens, no posicionamento do narrador, na delimitação do tempo e do espaço, no desenvolvimento da ação e da intriga, criando assim um novo realismo, que denomina "perspetivístico, fragmentário e de timbre lúdico" (REAL, 2012, p. 13).

Para Real, o romance luso da primeira década do século XXI representa a atual sociedade portuguesa cosmopolita, que não permite mais a existência 
de um genuíno romance português, pois apresenta múltiplas e universais categorias estéticas, sem buscar uma unidade. Gonçalo M. Tavares é um representante deste romance, predominantemente urbano, que explora temas universais e centra-se em espaços exteriores à realidade nacional, inovando na escolha de temas, na escolha do estilo e da estrutura. Se os escritores lusos contemporâneos se internacionalizaram por não estarem mais voltados exclusivamente ao público português, o mesmo ocorre com a tetralogia tavariana, narrada em um tempo difuso, perdido no século XX pós-guerra, em um espaço europeu incerto, que constrói (e destrói) personagens com nomes e sobrenomes judaicos e alemães.

Real também ressalta que Gonçalo Tavares, em sua produção estética autônoma, faz parte de um conjunto social e cultural, que tem por fundamento a desconstrução de um antigo conceito de realismo para a criação de um novo realismo, que reflete a mudança social portuguesa, que antes dos anos 60, contava com um público leitor minoritário, letrado e intelectualizado, e que se transformou em uma coletividade mais generalista, iletrada e transversal a todas as classes sociais no início do século XXI.

O romance contemporâneo português, como obra de arte, desalinha as certezas cristalizadas do leitor, atacando sua mente e sensibilidade através de interrogações existenciais de natureza social, política, religiosa e ideológica, ampliando, assim, o horizonte cultural por meio da perturbação estética, sendo este também o principal objetivo da produção tavariana: promover o trabalho da interpretação. "A literatura é perversão, no sentido de que o gesto literário significa percorrer o verso, o lado contrário das coisas: fazer ver justamente aquilo que não está à mostra" (LORENZATTO, 2014, s/p.).

Real (2012) salienta que na narrativa contemporânea, que se passa predominantemente em uma atualidade cosmopolita e globalizada, já não cabem divisões entre o rural e o urbano, entre clássicos e modernos, ou racionalistas e supersticiosos. E dessa forma, emergem novos escritores, com novas temáticas e estilos, refletores de novos costumes, em que cada autor segue a sua consciência estética, liberto da militância ideológica neorrealista que representava uma sociedade inerte. A diferença está no aprofundamento das formas e dos conteúdos: "Portugal vive hoje, nesta primeira década do século, no campo do romance, uma verdadeira época de ouro, tanto em quantidade como em qualidade" (REAL, 2012, p. 210).

O romance é um descendente vanguardista da epopeia, cujo herói moderno é um sujeito que vivencia conflitos existenciais e problemas imanentes a qualquer ser humano, podendo conceder sua voz aos marginalizados e oprimidos. Como elucida Freitas (2014), o gênero romanesco, adapta-se à realidade histórico-social e coloca a individualidade e as circunstâncias cotidianas no centro da narrativa, revelando que a vida do homem comum também é digna de ser representada, através da manifestação de traços psicológicos humanos, da revelação de uma realidade social, ou da expressão de um universo cultural.

Consoante a essa tendência, Gonçalo M. Tavares (MELLO, 2010), em sua tetralogia $O$ reino, compreende as ressonâncias da história em sua produção literária, buscando diluir as fronteiras entre a ficção e a não ficção, pois a arte pode provocar a mudança a partir de dentro. "O autor relata um passado de guerra e de trauma interpretado à luz do presente, híbrido, cúmplice e distante, registrado e contestado, como um diálogo ainda em andamento" (BRITO, 2015, p. 255).

A obra tavariana reflete o individual e o coletivo, sem buscar respostas únicas que reduzam essa complexidade, posto que a verdade e a moral são ambíguas. Os processos psíquico-sociais interferem nas ações dos personagens e na sua inserção no convívio em comunidade, de certa forma, traduzem o individualismo da realidade contemporânea. Tavares critica a atual sociedade capitalista, burguesa, informacional, pós-industrial através da retomada de fatos históricos, como o espaço da guerra. Entretanto, o paralelo 
traçado entre realidade e ficção é instável, com dados reinterpretados em um outro tempo e um local inominável. Frente a esta descontinuidade, é impossível separar a ordem e o caos.

\section{O reino no universo tavariano}

Gonçalo Tavares (VICTOR, 2010, s/p) nega que seus "livros pretos" retratem a descrença na humanidade, pois compreende que maldade e bondade são intrínsecas ao ser humano, como "dois motores em funcionamento". A natureza humana, não é binária, bons versus maus, uma vez que ações devem ser pensadas a partir de sua complexidade, abrangendo múltiplos ângulos de análise, como se percebe no desenvolvimento da tetralogia.

Para Tavares, o exemplo mais concreto dessa dicotomia foi vivenciada no extermínio da Segunda Guerra Mundial, em que a racionalidade e a inteligência de cientistas brilhantes foram aplicadas em ações de imensa brutalidade. "Me parece que depois disso não podemos escrever livros ingênuos e inocentes" (VICTOR, 2010, s/p). E como Galeano (2000) salienta, é necessário lembrar do passado para libertar (nos) de suas maldições e desprender o futuro de suas armadilhas.

A tetralogia tavariana ressalta que, em situações extremas, qualquer um pode praticar ações cruéis e inesperadas, por isso a necessidade da reflexão e do autoconhecimento, negando, assim, a ideia equivocada da ininterrupta bondade humana.

E o que eu gostaria é que esses livros servissem para que os leitores percebessem melhor o funcionamento dos seus motores, soubessem como é que se pode reduzir a velocidade do motor da maldade que nós temos, como é que se pode travá-lo, como é que se pode desviar a aplicação da sua força. Acho que isso é muito mais útil do que partir da ideia, errada, de que somos bons, feitos de outra massa que não a igual a daquelas pessoas terríveis. Acho que isso é que é perigoso: se nós assumirmos que nunca iremos praticar uma maldade... São as pessoas que assumem isso que mais rapidamente entram em atos absolutamente terríveis. Porque também são ingênuas, a ingenuidade tem a ver com isso, com a pessoa pensar que é boa até o fim dos seus dias. E nossa vida está sempre em questão (VICTOR, 2010, s/p.).

Nietzsche, em A genealogia da moral (2009), nega a polarização entre "o bem e o mal", pois ambos contribuem para o desenvolvimento humano, sendo errôneo conceituar o bem como algo positivo e cultivado e o mal como negativo e reprimido. 0 filósofo alemão alerta para a necessidade de saber utilizar, de maneira mais adequada ao convívio, essas duas forças existentes: "O sentido de toda a cultura é justamente domesticar a besta humana para fazer um animal pacato e civilizado" (2009, p. 45). Complementando este posicionamento, também nos mostra Freud (2012) que a cultura pode encobrir o impulso humano, mas ele permanece lá, perceptível e o conflito entre a cultura e o instinto é que leva a reflexão do que pode ou não ser feito segundo uma aceitação social.

Essa denominação 'livros pretos' se deve ao fato de a primeira edição da série ter sido publicada em Portugal pela Caminho em uma edição com a capa e a contracapa totalmente negras, apenas com o título da obra, nome do autor e editora em cor branca. No entanto, Tavares também explica que O reino faz parte dos livros pretos, mas poderão existir outros que também tratarão sobre a esfera mais obscura do ser humano e que não se inserem na tetralogia. Assim, os livros pretos formam uma coleção sobre medo e violência, da qual $O$ reino faz parte (RODRIGUES, 2011, s/p.).

Miguel Real (2012) define Tavares como um escritor racionalista, intelectual e filósofo de conceitos abstratos, no entanto, não são todos os livros de Gonçalo que são compostos por uma escrita labiríntica. Um homem Klaus Klump, apesar do conteúdo extremamente filosófico, em que frases 
simples incentivam a ponderação sobre conceitos complexos, como “Depois da História não há geografia” (TAVARES, 2007, p. 7), a maneira de organizar o texto ocorre predominantemente a partir de períodos simples como este citado recentemente. $\mathrm{O}$ crítico literário define muito bem a profusão de elementos que levam a questionar a racionalidade e a consciência:

O conteúdo de seus livros revela um alargamento dos limites do horizonte da literatura enquanto trabalho de e sobre a palavra, arrastando o leitor para um novo plano estético. E se o trabalho sobre a palavra pode corresponder a uma inovação estética, esta consolida-se e torna-se definitiva, vingando no estilo próprio do autor, quando a palavra corresponde igualmente a um jogo de ideias sólidas, ideias filosóficas, não apenas manipulações de sentido conotativo, em florões sucessivos ou em torrentes caudalosas de frases sobre frases (uma espécie de cultismo barroco), evidenciando os paradoxos morais de um pensamento lógico aplicado a situações da vida cotidiana e explorado nas suas ambiguidades conclusivas, mostrando tanto ser excessivamente tênue, a linha separadora entre razão e loucura quanto, não raro, ser através das obsessões, paixões, furores, manias, que a razão, ela própria, progride (REAL, 2012, p. 212).

Daí a possibilidade de relacionar a construção de $O$ reino com conceitos das obras de Nietzsche, Freud e Foucault, dado que Tavares propõe o desconcerto e a desarmonia do homem que se pretende racional e, no entanto, tem consciência de sua predominante irracionalidade oculta.

Como define Miguel Real (2012, p. 213) são "romances civilizacionais que evidenciam a existência de um Homem-Máquina, um HomemTécnica, insensível às emoções e aos valores humanistas da modernidade, cartografando um mapa europeu da memória do terror". O espaço é o mesmo do início ao fim: a pacata cidade, que nos dois primeiros livros ainda vive o conflito da guerra, e que em nos dois últimos revela as consequências e as lembranças traumáticas.

Ao longo da narrativa, há poucos elementos espaciais em destaque: as residências dos personagens, a prisão, a igreja, a escola, o hospício, a mata, a fábrica, o hospital, a rua do cavalo morto que se deteriora há meses, a sede do partido. Não há um maior detalhamento sobre a relação entre estes diversos pontos, as referências por vezes se relacionam em episódios específicos, como por exemplo, o cavalo que aparece na primeira e na segunda obra da tetralogia, a igreja na terceira e na quarta, o hospício na primeira, na terceira e na quarta. Apesar de tudo, rabiscar um mapa deste lugar seria tarefa quase impossível, pois cada obra apresenta um universo particular que não permite cruzar as informações entre elas e obter uma imagem gráfica homogênea.

O foco está nos acontecimentos que modificam as personagens, pois a realidade já não é a mesma depois do conflito, nem na cidade, nem na mata, o evento deixou suas marcas por toda a parte: Alof não consegue retomar a sua carreira, Johana, sem vez ou voz, será esquecida para sempre no manicômio; Klaus e Herthe se tornam os manipuladores dos destinos alheios. A realidade (des)estrutura o ser humano. Na terceira obra da série, a guerra já está concluída, contudo, mantem terríveis marcas nos sobreviventes. Diante de uma experiência de brutalidade, o tempo não extingue todos os traumas.

O tempo também oscila entre o seu caráter cronológico e psicológico. Os sete anos da prisão de Klaus parece muito menor ao seu aprendizado através do sofrimento, que modifica seus sentimentos, pensamentos, palavras e, inclusive, seu físico. 0 tempo não deteriora lentamente apenas o cavalo no meio da rua. Configuração similar a esse paralelismo entre o tempo factual e o imaginário ocorre com a estadia de Mylia no Georg Rosenberg e o processo de domesticação que sofre, assim como a doença fulminante que leva lentamente a força e o poder de Lenz Buchmann. Essa rarefação do tempo e do espaço, segundo Miguel Real (2012), sugere a decadência de uma civilização inteira, postulando o século XX como a decadência europeia, agora desprovida de valores transcendentais, como Deus, Verdade, Justiça e Bem. 


\section{Interrogações sociais, culturais, políticas e ideológicas}

Desde o início da narrativa, a mulher não possui os mesmos direitos que o homem. Johana é humilhada quando entra em um bar para beber, local e ação de uso exclusivo do gênero masculino. Após o início da guerra, essa situação só piora, pois a mulher passa a ser vista como objeto do homem que partiu, é agredida e, frágil, não pode lutar, passando a ser tratada como inativa, desrespeitada perde sua dignidade: "Os homens que são mais fortes entram para o exército, os homens que são mais fortes violam as mulheres que ficaram para trás, as mulheres dos inimigos que fugiam" (TAVARES, 2007, p. 9)

A necessidade de sobrevivência gera a adaptação e a mudança: a mulher que não quer morrer precisa se fortalecer, enquanto os 'seus' homens não retornam, desenvolve a própria maneira de resistir. "A brutalidade instalouse e já não magoa ninguém" (TAVARES, 2007, p. 48). Como o pressuposto da evolução das espécies, não é o mais forte que sobrevive, mas o que melhor se adapta, e a mulher, de frágil só tem a aparência, pois é a sua astúcia que a torna apta a dominar, como ocorre com Herthe e Júlia. A que não consegue evoluir, acaba perecendo, como Johana e Mylia.

Apesar do conflito instaurado, Klaus tenta se manter neutro, pois "um homem durante a guerra deve ser surdo-mudo até se possível” (TAVARES, 2007, p. 18). Ele não é um homem alienado, seu trabalho é editar livros contrários à política e à economia vigente. Mas acredita que, um homem que decide colocar a própria vida em risco deve ter fortes ideais. O conflito da narrativa se inicia quando mexem na pátria de Klaus: ele vai para a floresta, vingar o estupro de sua namorada: Johana, mas a sucessão dos fatos faz com que esta motivação inicial se perca ao longo do tempo.

O processo de fortalecimento de Klaus é concomitante ao enfraquecimento de Johana, até a sua loucura. O casal segue caminhos opostos, em que não há mais lugar para sentimentalismos, apenas racionalidade ou falta dela. "Já não existiam paixões com prestígio a não ser o pensamento em vingar-se." (TAVARES, 2007, p. 25). Só que a vingança, apesar de ser o impulso, não trará a resolução, pois "como é que fazer sofrer pode ser uma reparação?" (NIETZSCHE, 2009, p. 73).

Com a guerra, Klaus tornou-se um estrategista. Ele possui duas faces: a coletiva e a individual. É "Um Homem”, como define o título, sujeito que luta para atingir seus objetivos. No passado, integrou-se a uma comunidade que lutava contra a guerra, fazia parte de um grupo que o resgatou da prisão. Após enfrentar diversos obstáculos e deixar várias pessoas de suas relações para trás, desenvolveu seu egocentrismo. A pátria de Klaus deixou de ser a família, o amor, o ideal, o grupo, e passou a ser o seu progresso individual, adaptandose a esse mundo fragmentado pela modernidade e caótico pela guerra.

A maneira como as personagens se encontram e se desencontram na trama também é bastante significativa. Johana está fadada à solidão: encontra-se e perde-se de Klaus, depois o mesmo ocorre entre ela e Ivor. Herthe era a antagonista de Klaus, que o traiu e o conduziu à prisão, na fase em que possuíam objetivos opostos. Entretanto, quando ele se torna o grande empresário, a poderosa viúva herdeira do império se torna sua aliada. Herthe e Klaus têm a aptidão de manipular as ações para as reações os favorecerem.

Johana teve a sua vida desfeita em função das reviravoltas que a guerra efetuou. Em relação à sua intimidade, primeiramente vivia feliz com Klaus até que foi estuprada por Ivor, e seguiu por sete anos sob a sua proteção e dependência. O oficial que 'frequentava Johana' já não necessitava levar outros soldados consigo, agora ela era sua amante, os seus colegas respeitavam 'isso' e Johana também, afinal não tinha opções.

Ivor ocupara sem sentimentos nem cerimônias o lugar que antes estava cedido a Klaus, tornando-se o responsável pelos remédios de Catharina, 
enquanto Johana vivia enclausurada, a cuidar da mãe e a protegê-la de sua obsessão por lâminas. Tudo parecia resolvido e acabado, nunca mais tivera notícias de Klaus, na sua visão, ele simplesmente desaparecera no dia em que fora para mata.

Quando Klaus fugiu da prisão, retornou para a casa de Johana, para uma noite de amor, consentida ou obrigada? Teria mesmo a moça, desta vez, opção de escolha? Em tempos diferentes, a mesma situação se repete ao contrário, espelhada, e Johana novamente no papel de objeto possuído e descartado, que findará os seus dias no famoso hospital psiquiátrico Georg Rosenberg.

Ela já vivera isso anteriormente, sabia o que estava prestes a acontecer, não chorou, já não era a menina fraca de sete anos atrás, deu comida aos fugitivos, enquanto Klaus fumava em silêncio, observando uma fotografia de Ivor sobre a mesa. A lentidão das ações e a escassez das palavras neste episódio apenas sugerem os acontecimentos que levarão mãe e filha a uma paragem sem volta. A tensão, neste momento, ocorre através dos silêncios e dos olhares, o ato de despir-se e de "ir ali" como uma ação simples e inocente:

Xalak, no meio de um discurso ininterrupto, diz, fico com a outra - e olha, então, para a porta do quarto onde está a mãe de Johana. Johana olha para Klaus. Klaus continua sentado.

Xalak despe-se completamente. Johana baixa os olhos. Xalak pede o cigarro a Klaus. Aspira uma vez o cigarro e devolve-o. Vou ali, diz Xalak, e dirige-se ao quarto. Klaus mantém-se na mesma posição, diz-lhe: fecha a porta por dentro. (...)

Johana está parada no chão, a olhar para Klaus. Treme. Não se consegue mexer. Está a tremer muito, um tremor estranho, íntimo (TAVARES, 2007, p. 68).

No início, Ivor pareceu preocupado em auxiliar as mulheres a recuperarem-se do ocorrido, mas logo desinteressou-se de Johana, diagnosticou-a como louca, assim como a mãe, e desde esse dia, nunca mais se viram. Johana que iniciou a narrativa erguendo a sua voz, manipulada pelos desejos masculinos, excluída da sociedade, trocou a clausura do zelo com a mãe ao confinamento e à solidão do Georg Rosenberg, visto que depois da guerra não lhe restara nada nem ninguém.

Comportamento oposto possui Herthe, prostituta que entrega os foragidos aos policiais, mas não é uma iniciante ingênua, sua função é ser o ímã que conduz à prisão. Ela simulava ser manipulada pelos militares, entretanto, criou estratégias, ganhou privilégios, conquistou seu espaço, e conseguiu realizar um excelente casamento, tornando-se, em seguida, a viúva respeitada, e, posteriormente a esposa bem-sucedida de Leo Vast.

A ex-prostituta conduziu o marido para a morte, ao mesmo tempo em que não permitiu que o irmão fugisse novamente. Tudo foi planejado pela força feminina incomum naquele contexto. É a mesma força que concedeu a Julia, como recompensa por cuidar de Lenz Buchmann, o recebimento de sua herança no encerramento da tetralogia.

Herthe foi a personagem que melhor usou o seu corpo para obter vantagens, valendo-se da sedução: "Ninguém escapa à lógica econômica. Os ganhos, as perdas, o lucro. Poderá a tua moeda ser estranha - o teu corpo, por exemplo - mas é moeda: utensílio de troca” (TAVARES, 2007, p. 82). E ela soube usar essa estratégia até se tornar a grande herdeira do Império Leo Vast.

Michel Foucault, nos diversos estudos em que aborda direta ou indiretamente a questão do corpo, não o apresenta como mero formato da existência, ou seja, uma visão fisiológica da função corporal, mas percebe forças em atrito que envolvem variados mecanismos. Os inúmeros episódios que evidenciam a importância do corpo na tetralogia de Tavares, leva-nos a problematizá-lo, pois assim como em Foucault (2008) relaciona-se com determinadas ações, saberes, estratégias, práticas sociais e políticas.

Em geral, as personagens de $O$ reino não apresentam muitas descrições físicas, a menos que elas sejam importantes, como no caso de Klaus, um 
homem alto. Essa característica assinala a sua capacidade de ver além, pois seu olhar se direciona a partir de um ponto mais acima: "Conheceu Johana porque ela olhou por cima de uma sebe verdíssima e olhou por cima de uma Primavera ainda mais verde que a sebe" (TAVARES, 2007, p. 14).

Na mata, os lábios de Klump ficam pretos e ele falava palavras pretas que queimavam a boca. "Os lábios escureceram ao mesmo ritmo que o interior do corpo, dizia Klaus, quase divertido" (TAVARES, 2007, p. 61). Klaus era um homem das palavras, na floresta foi emudecendo, na prisão endurecendo as poucas palavras que pronunciava.

Lenz, o protagonista de Aprender a rezar na era da técnica descreve o corpo como um mapa, percebendo no cérebro a sua a arma de defesa. Médico neurologista, com seu bisturi invade os corpos, as cabeças, para tentar restabelecer a ordem, em um combate da técnica contra a doença. Ao dr. Buchmann, ter a vida e a morte nas suas mãos lhe dava prazer, estava vivo, era rico e forte, esse era o seu ofício, que realizava com exatidão, por isso, não queria agradecimentos. Ele não era um homem bom, gostava de humilhar mulheres, prostitutas, adolescentes e pedintes. É a tendência do ser humano ao mal, à agressão e à destruição como explica Freud: “(...) se apenas puder satisfazer algum prazer com isso, não se importará em zombar de mim, me ofender, me caluniar, me mostrar que tem poder sobre mim, e (...) quanto mais desamparado eu for, tanto mais devo esperar esse comportamento de sua parte em relação a mim" (FREUD, 2012, p. 121).

0 renomado dr. Lenz tinha um ritual de humilhação ao mendigo: chamava-o para sentar-se à mesa, lia-lhe as notícias, oferecia-lhe dinheiro e comida, mas antes o outro precisava cantar o hino e observar o médico tendo relações sexuais com a esposa. Repetira essa ação por meses com o mesmo homem. Até sentir-se fascinado pelo louco Rafa. Rafa não aceitou somente olhar Lenz tocando sua mulher, é ele quem queria fazer aquilo. Lenz, como bom caçador, agiu rápido e, assim que o louco a tocou, com a arma de caça foi morto com um tiro na cabeça. Buchmann pensa por breves segundos e também atira na cabeça da esposa.

É uma mente extremamente racional que reorganiza os corpos para que sua versão seja creditada, como se montasse um cenário a ser contemplado de cima. Contou à polícia que estava sendo roubado e que Rafa matou sua mulher e, após uma disputa, Lenz o matara em legítima defesa. Aos olhos do povo, seu suposto sofrimento promoveu ainda mais sua notoriedade política.

Aprender a rezar na Era da Técnica leva à reflexão sobre a manipulação das informações frente as massas, pois como Freud esclarece, "a convivência humana só se torna possível quando se reúne uma maioria que é mais forte do que cada indivíduo e que permanece unida contra cada um deles" (2012, p. 97). E a maioria foi manipulada pelo jogo individual de Buchmann, que faz da sua verdade, a única visível.

\section{A linha tênue que separa razão e insanidade}

Como podemos definir a loucura? Seria a fuga da realidade? Manias e obsessões definiriam a (in)sanidade? Catharina, mãe de Johana, é considerada louca por suas atitudes descabidas, mas evidencia uma interpretação sensata ao querer interferir nas máquinas que causam o desastre. Ela queria consertar os tanques, fazendo-os rebentar para dentro, a tentativa alienada de alcançar sua meta com a ponta de uma agulha quente manifesta o seu anseio racional em acabar com a guerra. É o mesmo pensamento ingênuo que acompanha Joseph Walser, ao concluir que ao ter em mãos uma peça que antes compunha uma arma, está interferindo na guerra, pois esta já não poderá mais funcionar. Ainda que não esteja contribuindo de forma alguma no evento, analisa-o de maneira crítica.

Como definir a tênue linha que separa as manias das patologias? São inúmeros os comportamentos repetidos e, muitas vezes, incompreensíveis 
ao longo da tetralogia: Catharina e a agulha, Ortho e sua memória obsessiva para os livros e a matemática, Joseph e a coleção, Klober e seu desfecho neriano, Mylia e a dor que não lhe mata, Hinnerk e os instintos assassinos, Lenz e a perversão sexual, entre tantos outros.

Walser é alheio a tudo, refugiando-se com frequência em seu mundo particular, universo da sua coleção, composta por mais de cinquenta prateleiras com objetos catalogados e etiquetados, todos com menos de dez centímetros de altura, largura ou comprimento, sem nenhuma utilidade aparente, mas com incalculável valor afetivo. Essa fixação o transporta para um ambiente de calma e alegria, em um simples girar da chave. É comum que o ser humano "(...) se agarre aos seus objetos e obtenha a felicidade a partir de uma relação afetiva com eles” (FREUD, 2010, p. 73).

Joseph, sempre absorto, ouvia muito, falava pouco. Só se concentrava no exterior quando lidava com a sua perigosa máquina, que lhe exigia gestos determinados, repetidos e de sequência constante. Ele próprio se confundia com uma máquina, essa que era sua inimiga, a esperar por um descuido seu, mas ao mesmo tempo, era um objeto que admirava, que considerava superior, devido a sua precisão. "As máquinas começam a ter autonomia, as ideias não. [Elas] interferem já na História do país e também na nossa biografia individual." (TAVARES, 2010, p. 15). Walser concedia a elas um caráter titânico, que ia além de suas próprias capacidades humanas, esquecendo-se que foi e sempre será um instrumento inventado e administrado pelas pessoas.

Seu comportamento resignado não permite que responda ao chefe, contrarie a esposa, apático, até mesmo nos momentos instáveis, como no dia em que descobre que está sendo traído por sua mulher com seu encarregado. Esboça uma perturbação, pensa, mas não age, guardando as emoções como a coleção, fechada a chave em seu escritório. Indiferença que ocultava diversos conflitos, apaziguados pela afeição aos objetos.
Em um dia de trabalho como outro qualquer, seu casaco engancha na máquina e ele perde o dedo indicador da mão direita. Ainda sem saber como adaptar-se a essa perda, ainda no hospital, a obsessão pela coleção não diminuiu e se esforça para capturar uma peça que se encontra ao pé da cama. De volta ao trabalho, se culpa por ter que desempenhar outra função, sente falta de sua máquina. É o trabalho alienado que aliena a natureza do homem, como propunha Marx.

Jerusalém é o terceiro livro da tetralogia, que apresenta os detalhes do cotidiano do Hospital Psiquiátrico Georg Rosemberg. Dentro do espaço do hospício, algumas regras sociais recebem uma punição maior do que fora deste ambiente de vigilância: Mylia e Ernst relacionam-se sexualmente na frente dos outros internos e, por consequência, nasce Kaas, um herdeiro deficiente. O ex-marido de Mylia, aceita criar esse filho ilegítimo, mas a paciente paga seu ato com a reclusão no regime de isolamento e a esterilização sem o seu consentimento. Jerusalém delineia um percurso em que a loucura, a solidão, a dor e a previsão de uma morte que jamais chega, prolongando assim um sofrimento sem data de término, questionando, assim, os limites do humano. Fora dos muros do manicômio, Hinnerk Obst personifica o colapso que a guerra pode gerar no psicológico de um veterano de guerra, perambulando, perdido em si e de si, escondendo o seu medo atrás de uma arma, prestes a disparar ao menor vestígio.

Neste contexto, a liberdade, a saúde, os pensamentos, o próprio corpo não pertencem mais ao paciente, pois quem determina cada detalhe da existência e a habilidade médica, como esclarece o dr. Busbeck: "O médico sou eu, não te esqueças. Eu que determino quando é que as pessoas estão saudáveis ou doentes. No limite sou eu - como médico - que determino quem está morto" (TAVARES, 2011, p. 43). De acordo com Costa, a loucura, a solidão, o medo e a violência estão por toda a parte, não existe um local possível para se proteger das consequências da barbárie: “Os loucos que passam por Georg 
Rosenberg, por sua vez, em sua errância e imprevisibilidade, permitem ver que, no espaço aberto da cidade ou cercados pelos muros do Hospício, não há liberdade ou apaziguamento da dor em um mundo de regras absurdas" (COSTA, 2010, p. 103).

\section{Considerações finais: o romance português analisa a sociedade contemporânea}

A tetralogia tavariana evidencia a dualidade entre o individualismo e a necessidade do outro. Cada personagem é independente, mas necessita de alguém que o fortaleça, ainda que esta relação com a alteridade se mostre, muitas vezes, inviável. É Mylia quem declara: "Ajo para mim, atuo como se vivesse em frente ao espelho. Egoísmo, ou afinal, boa economia dos impulsos" (TAVARES, 2011, p. 12).

Mas, diante do perigo, Mylia chama Ernst, que, por sua vez, desiste do suicídio. Hannah cuida de Hinnerk, mas também não tem quem cuide de si mesma. Ou ainda, o dr. Busbeck, que investe anos em seu estudo tentando compreender a mente humana e suas consequências trágicas, mas acaba completamente sozinho no final da narrativa, sem entender a si próprio, a ex-mulher, seu filho adotivo.

A aspiração pela felicidade é egoísta, mas está em contato com a aspiração pela união com a comunidade que é altruísta. A cultura restringe, põe regras nas ações individuais, é a ética que rege os seres humanos entre si. (...) é assim que os dois processos de desenvolvimento, o individual e o cultural, têm de se hostilizar e disputar o terreno um do outro (FREUD, 2012, p. 176).

Em Jerusalém, todos estão a procurar algo durante a madrugada. Mylia procura uma igreja. Ernst procura Mylia. Theodor procura uma prostituta. Hannah procura clientes. Hinnerk procura o cliente de Hannah, Kaas procura pelo pai. Todos enfrentam a noite fria e escura, algo que não está totalmente definido, que não é plenamente consciente, busca-se o outro ou a si mesmo? São seres em transformação, fragmentados, ora representam uma classe, ora seu individualismo, ora subvertem o que proclamavam antes.

A tetralogia evidencia uma dependência da máquina, a elevação do ego pelo conhecimento, pelo poder, pelo dinheiro ou pela técnica, a exploração do outro, mas afetividade não há. $O$ reino termina sem deixar sequer um herdeiro.

A parcela de realidade por trás disso tudo, que se prefere recusar, consiste no fato de que o ser humano não é uma criatura afável e carente de amor que, no máximo é capaz de se defender quando atacada, mas que ele pode contar com uma cota considerável de tendência agressiva no seu dote de impulsos. Por esse motivo, o próximo não é apenas um possível ajudante e um possível objeto sexual, mas também uma tentação para se satisfazer nele a agressão, explorar sua força de trabalho sem recompensá-lo, usá-lo sexualmente sem o seu consentimento, apropriar-se de seus bens, humilhá-lo, causar-lhe dor, torturá-lo e matá-lo. Homo homini lupus. (FREUD 2012, p. 123-124).

Os personagens de o $O$ reino não criam vínculos, pois "a proteção mais imediata contra o sofrimento que pode resultar das ações humanas é a solidão voluntária, o distanciamento em relação aos outro" (FREUD, 2012, p. 65). Em $O$ reino, é a violência que gera a reflexão, diante dos horrores da guerra, o ser humano abandonado, solitário e indefeso, tem por única alternativa endurecer. Tudo é difuso, insólito, a razão e a emoção estão desajustadas, nada é compreensível ou justificável.

Por tudo que foi exposto, percebemos que Tavares se insere na tendência contemporânea da literatura portuguesa de pensar a atualidade, de conduzir o leitor à reflexão de sua realidade, relacionando a literatura com a filosofia, a psicologia, a sociologia e tantas outras áreas do conhecimento, que possibilitem a uma melhor conscientização da natureza humana, deste 
seu lado mais obscuro, mas recorrente, relacionando a literatura com a filosofia, a psicologia, a sociologia e tantas outras áreas do conhecimento, que possibilitem a uma melhor conscientização da nova barbárie ainda existe. "Na pior das hipóteses, o holocausto é atribuído a uma predisposição 'natural', primitiva e culturalmente inextinguível da espécie humana" (BAUMAN, 1998, p. 20).

Dessa forma, conhecer-se a si mesmo, refletir sobre o passado, avaliar o presente, analisando a sociedade contemporânea e a multiplicidade do comportamento humano, faz-se necessário. Tavares cumpre este papel tanto na tetralogia quanto em tantos outros textos de sua extensa produção.

\section{Referências}

BAUMAN, Zygmunt. Modernidade e holocausto. Rio de Janeiro: Jorge Zahar, 1998.

BORGES, Jorge Luiz. Cinco visões pessoais. Brasília: Editora Universidade de Brasília, 1985.

BRITO, Sandra Beatriz Salenave de. 0 reino de Gonçalo M. Tavares e a voz dos silenciados no espaço da guerra. Grau Zero: revista de crítica cultural. Bahia, v. 3, n. 1, p. 244-258. jan.-jun. 2015. Disponível em: <http://revistas.uneb.br/index.php/grauzero/article/ view/2101/1442>.

COSTA, Erick Gontijo. $O$ mundo em ruínas: as zonas cinzentas na escrita de Gonzalo Tavares. Kalíope, São Paulo, ano 6, n. 12, p. 101-106, ago-dez. 2010.

COSTA, Carlos; BESSANA, Dyda Bessana. O homem que deu inveja a Saramago. 26 abr. 2015. Disponível em: <http://didabessana.wixsite.com/historiasdolivro\#!O-HOMEM-QUEDEU-INVEJA-A-SARAMAGO/cy8f/5536e46a0cf2adc1acdac6d5>. Acesso em: 27 jun. 2016.

FOUCAULT, M. Vigiar e punir. Rio de Janeiro: Vozes, 2008.

FREITAS, Elizete Albina Ferreira de. O romance português contemporâneo: ideário e trajetória estética de Lídia Jorge. 210 f. Tese (Doutorado) - Programa de Pós-Graduação em Letras e Linguística, Faculdade de Letras (FL), Universidade Federal de Goiás, Goiânia, 2014. Disponível em: <https://repositorio.bc.ufg.br/tede/bitstream/tede/4292/ 5/Tese\%20-\%20Elizete\%20Albina\%20Ferreira\%20de\%20Freitas\%20-\%202014.pdf>. Acesso em: 31 mar. 2016.
FREUD. Sigmund. O mal estar na cultura. Porto Alegre: L\&PM Pocket, 2012.

GALEANO, Eduardo. De pernas pro ar: a escola do mundo ao avesso. Porto Alegre: L\&PM 2000.

LORENZATTO, Bruno. Gonçalo Tavares: a literatura para percorrer o verso. Outras Palavras. 14 maio 2014. Disponível em: <http://outraspalavras.net/posts/a-literaturaperversora-de-goncalo-tavares/>. Acesso em: 13 ago. 2016.

MELLO, Ramon. Gonçalo M. Tavares: literatura como projeto de vida. Editora Saraiva. Criação em 22 jun. 2010. Disponível em: www.saraivaconteudo.com.br/Entrevistas/ Post/10333. Acesso em 30/04/2014.

NIETZSCHE, Friedrich. Genealogia da moral. 3. ed. São Paulo: Escala, 2009. (Coleção Grandes obras do pensamento universal).

REAL, Miguel. O romance contemporâneo português (1950-2010). 2. ed. Lisboa: Caminho, 2012.

RODRIGUES, Sérgio. Gonçalo M. Tavares e a glória do português.. Revista Veja/blog Todo prosa. Criado em 03 set. 2011b. Disponível em: <http://veja.abril.com.br/blog/meuslivros/entrevista/goncalo-m-tavares-e-a-gloria-do-portugues/>. Acesso em: 28 abr. 2014. TAVARES, Gonçalo M. A máquina de Joseph Walser. São Paulo: Companhia das Letras, 2010 .

. Aprender a rezar na era da técnica. São Paulo: Companhia das Letras, 2008

Jerusalém. São Paulo: Companhia das Letras, 2011.

Um homem: Klaus Klump. São Paulo: Companhia das Letras, 2007.

TRIGO, Luciano. O meu trabalho é iluminar palavras. Rede Globo, blog Máquina de Escrever. Criação em 09 fev. 2014. Disponível em: <http://g1.globo.com/platb/ maquinad eescrever/2014/02/09/goncalo-m-tavares-o-meu-trabalho-e-iluminarpalavras/>. Acesso em: 29 abr. 2014.

VICTOR, Fábio. Português Gonçalo M. Tavares fala sobre maldade, Saramago e Brasil. Folha de São Paulo, 17 jul. 2010. Disponível em: <http://www1.folha.uol.com.br/ ilustrada/2010/07/767901-portugues-goncalo-m-tavares-fala-sobre-maldade-saramagoe-o-brasil.shtml?mobile>. Acesso em: 03 maio 2014

Recebido em 28/08/2016.

Aceito em 30/09/2017. 